\title{
Budget Template for Home Canning ${ }^{1}$
}

Kevin R. Athearn, Amarat Simonne, and Soohyoun Ahn²

\section{Introduction}

Preserving fruits and vegetables by canning them in a home kitchen is a popular activity practiced by one in five US households (D'Sa et al. 2007). University of Florida IFAS Extension offers classes on home canning, with thousands of participants each year (Figure 1). At these classes, participants learn about canning methods and food safety precautions. Some participants, especially those planning a cottage food business, seek additional information about the economics of home canning. This article and template are intended to fill the need for considering the financial aspects of home canning.

The Budget Template for Home Canning is designed to assist you in estimating the cost and potential returns from canning food. If you are canning for your household's consumption or for gifting, you may want to know the full cost of the activity or how much money you are saving by doing it yourself. If you plan to sell canned foods, you probably want to know whether that venture will be profitable. Whatever your reason for canning, this budget template can help you decide whether canning is worthwhile for you.

Florida's cottage food law allows the sale of canned foods prepared in unlicensed kitchens, subject to certain restrictions. For example, jams and jellies are allowed, but salsas and barbecue sauces are not. Unlicensed sales under the cottage food law must be direct to consumers and may not exceed $\$ 50,000$ in gross sales per year (Florida

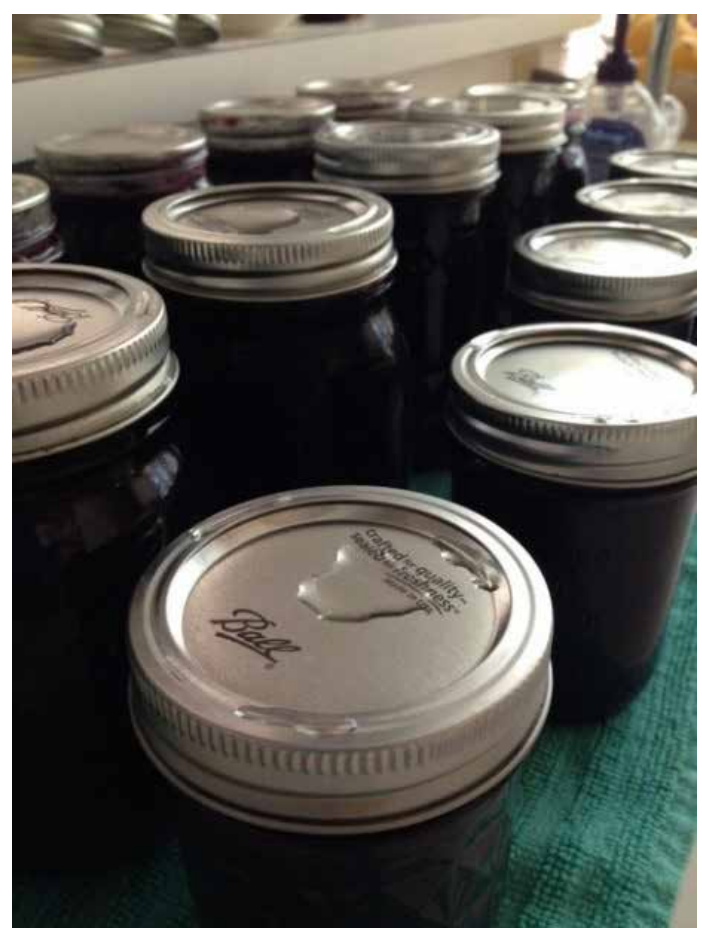

Legislature 2016; FDACS 2017). If you are selling canned foods through a cottage food operation following Florida guidelines, you can use the budget template to help you

1. Set the price of each product.

2. Choose the most profitable product or mix of products.

3. Estimate the profitability of the overall operation.

1. This is EDIS document FE1034, a publication of the Food and Resource Economics Department, UF/IFAS Extension. Published November 2017. Visit the EDIS website at http://edis.ifas.ufl.edu.

2. Kevin R. Athearn, regional Extension agent, Food and Resource Economics Department, Suwannee Valley Agricultural Extension Center, UF/IFAS Extension, Live Oak, FL. Amarat Simonne, professor, Department of Family, Youth and Community Sciences, UF/IFAS Extension, Gainesville, FL Soohyoun Ahn, assistant professor, Food Science and Human Nutrition Department, UF/IFAS Extension, Gainesville, FL 
Preparing budgets and estimating costs per jar can help you make financially informed decisions to benefit your small business.

The Budget Template for Home Canning includes a blank printable worksheet and completed example, as well as an interactive spreadsheet. You will need a pencil and calculator to complete the printable worksheet. If you have a computer, you can download the interactive spreadsheet and instructions from the North Florida Enterprise Budgets webpage: http://svaec.ifas.ufl.edu/featured-3-menus/ extension/agricultural-economics/north-florida-enterprisebudgets/. Fill in the yellow cells in the spreadsheet with your information, and the green cells will calculate automatically. You may use whichever format (printed or computer) you prefer.

Instructions are included in both the printable worksheet and the interactive spreadsheet. Further explanation and interpretation of the budget template are given below.

\section{The Budget Template}

Table 1 shows the blank budget template, and Table 2 shows an example of the template with the numbers filled in. The budget template has separate tables for batch specifications, costs, labor hours, sales revenue, and profitability analysis. Cost tables include ingredient costs, jar costs, durable supply and equipment ownership costs, equipment operating costs, and labor hours.

In the ingredient cost section of Table 1, list the ingredients needed (e.g., sugar), amount purchased (e.g., 10-pound bag), and cost of each purchase (e.g., \$9.00). Estimate the number of batches you could make from the amount purchased. To estimate this number precisely, you may need to convert units of measure (Table 3). Aqua-Calc (2017a, $2017 \mathrm{~b}$ ) provides websites where you can convert weights to volumes, and vice versa, for specific food products. As an example, a 10-pound bag of white, granulated sugar is equivalent to 22.68 cups. If a jam recipe calls for 7.5 cups of sugar, you can make approximately three batches of jam with the 10 -pound bag of sugar (i.e., $22.68 \div 7.5=3.024$ ). On the printed worksheet, calculate the cost per batch by dividing the cost of purchase by the number of batches. For sugar, $\$ 9.00$ divided by 3 batches equals $\$ 3.00$ per batch. The last step is to sum the cost per batch for each ingredient to obtain the total ingredient cost per batch.

Use the jar cost section of Table 1 only for jars, lids, bands, or labels that are not reusable (i.e., only used once, or sold and not returned). Use the durable supply and equipment ownership cost section of Table 1 for jars, lids, bands, or labels that are reusable (used more than once). For items that you list in the jar cost section of Table 1, enter the item (e.g., labels), the amount purchased (e.g., 60-count), the cost of purchase (e.g., \$6.00), and the number of batches you could make with the package purchased (e.g., $60 \div 8=$ 7.5). On the printed worksheet, divide the cost of purchase by the number of batches to obtain the cost per batch (e.g., $\$ 6.00 \div 7.5=\$ 0.80$ ). Sum the cost per batch for each item to obtain the total cost per batch for jar items that are not reusable.

In the durable supply and equipment ownership cost section of Table 1, list canning supplies and equipment that are usable for more than one batch. A basic set of canning equipment and durable supplies (not including the jars, stove, or other heating implement) costs approximately $\$ 90$. Enter the original cost (purchase price) of each item, and estimate the total number of batches over the lifetime of the item. If you will also use the supplies and equipment for other products, estimate the number of batches of all products for each item. On the printed worksheet, divide the original cost by the number of batches to calculate the cost per batch (e.g., $\$ 30 \div 60=\$ 0.50$ ). Sum the cost per batch for each item to obtain the total cost per batch for ownership of durable supplies and equipment.

In the equipment operating cost section of Table 1, estimate costs associated with using the durable supplies and equipment. The primary operating cost will be the needed energy (e.g., electricity or propane) to operate the stove or other equipment. A USDA study estimated the electricity needed to process green beans, peaches, and tomatoes in a 7-quart canner ranged from 1.6 to 2.4 kilowatt hours (Kendall and Payton 2008). Energy cost calculators found on the Internet can assist you in estimating energy costs (EnergyUseCalculater.com 2017; Peoples Gas 2017; US Department of Energy 2017).

For example, if the heating element on a stovetop uses an average of 1,500 watts ( 1.5 kilowatts) per hour of heating, and two hours of heating are needed to process a batch, the batch uses 3 kilowatt hours (kwh) of electricity. You can find the cost of electricity per kwh on your electric bill. Often electric bills include a fixed standby charge and a variable rate per kwh. Use the variable rate per $\mathrm{kwh}$ as the cost per unit (e.g., \$0.12). Multiplying the cost per unit by the number of units per batch gives you the operating cost per batch (e.g., $\$ 0.12 \times 3=\$ 0.36$ ).

In the labor hour section of Table 1, list the hours of time needed for each batch. You can break down the time by 
preparation time, processing time, and marketing time. List any hired labor in the cost per batch column of the labor hour section of Table 1.

The cost summary section of Table 1 combines the total costs per batch. All fields in this section of Table 1 are calculated automatically if you are using the interactive spreadsheet. If you are using a printed worksheet, sum the cost per batch for all the rows in each section of Table 1 , and enter the total cost per batch in the cost summary section of Table 1. Variable costs are the sum of the ingredient costs, jar costs, equipment-operating costs, and labor costs. Variable costs increase as you make more batches (but are constant per batch). Total costs are the variable costs plus the durable supply and equipment ownership costs (fixed costs). To calculate the cost per jar, divide the total costs per batch by the number of jars in the batch (e.g., $\$ 24.16 \div 8=$ \$3.02).

If you are selling the canned products, enter the selling price per jar and number of jars sold per batch in the sales revenue section of Table 1 . Multiplying the price per jar by the number of jars sold from the batch gives you the revenue per batch (e.g., $\$ 4.00 \times 8=\$ 32$ ).

The profitability analysis section of Table 1 is used to calculate net returns per batch, per jar, and per labor hour. Net returns can be calculated over variable costs or over total costs. The net return per batch is the sales revenue per batch minus the costs (variable or total) per batch. Divide the net return per batch by the number of jars per batch to obtain the net return per jar. Divide the net return per batch by the number of labor hours per batch to obtain the net return per labor hour.

\section{Interpreting Budgets for Decision Making}

If you are canning for your household's consumption or for gifting, the canning budget allows you to estimate savings or costs from doing your own canning. In the example budget, the total cost per batch is $\$ 26.46$, and the total cost per jar is $\$ 3.31$. If it would cost you $\$ 4.00$ to buy a jar of jam of equivalent quality at the store (for a gift or your own consumption), you save $\$ 0.69$ per jar by canning your own jam. Keep in mind that you spent some of your own time (unpaid) to obtain this savings. If you could buy a similar jar of jam at the store for $\$ 3.00$, then you end up paying $\$ 0.31$ more per jar by doing your own canning (and spending your own unpaid time). In that case, it may not be worthwhile for you to do your own canning, unless you gain other benefits, such as enjoyment of the activity, satisfaction of doing it yourself, or a higher quality product than what you could buy at the store.

If you are selling the canned products to earn income, the budget can help you set prices appropriately, choose the most profitable product mix, and evaluate the profitability of the overall operation. Other publications are available that provide additional guidance on starting and running a home-based food business (North Central Regional Extension 2000; Ahn et al. 2014a, 2014b).

The total cost per jar is also the breakeven price ( $\$ 3.31$ in the example). If you sell your jars for a price above the breakeven price, you are earning income on each jar sold. If you sell your jars for a price below the breakeven price, you are losing money on each jar sold. To be a viable business, you must set your price above the breakeven price. The difference between your selling price (e.g., \$4.00) and the breakeven price (e.g., \$3.31) is your net return per jar (e.g., \$0.69). If you already own the durable supplies and equipment needed for canning, those fixed ownership costs are considered sunk costs. In that case, any selling price above the variable cost per jar (e.g., \$3.02) will be earning a positive cash flow that offsets some of those sunk costs.

In setting prices, it is important to have a good understanding of your target market, what products and attributes they want, and how price sensitive they are. That is, a higher price that increases your net return per jar could reduce the number of jars customers will buy, while a lower price that decreases your net return per jar could increase the number of jars customers will buy. It may be helpful to estimate this price-quantity relationship for your products. For example, the difference between selling 16 jars per week at $\$ 5.00$ per jar and selling 24 jars per week at $\$ 4.00$ per jar. In this case, your sales revenue is $\$ 16$ higher at $\$ 4.00$ per jar ( $\$ 96$ revenue) than at $\$ 5.00$ per jar ( $\$ 80$ revenue). However, your variable costs increase as you produce more jars. At a variable cost per jar of $\$ 3.02$, your cost would increase by $\$ 24.16$ for producing 8 jars $(\$ 3.02 \times 8=\$ 24.16)$. In this example, your net return (profit) is higher when you sell 16 jars at $\$ 5.00$ each than when you sell 24 jars at $\$ 4.00$ each. Knowing your variable cost per jar can help you judge whether increasing production and sales is worth the additional costs.

Creating budgets for multiple products allows you to compare the profitability of the different products. You may choose to make a single product that has a high net return, or you may find that offering multiple products allows you to expand your market. If the amount you can produce is constrained by your own labor time (or other resource), 
making more of one product means less time is available to make other products. Calculating the net return per labor hour for each product can help you choose the most valuable use of your time and the most profitable product mix. For example, kumquat marmalade may earn a net return of $\$ 15$ per batch, whereas strawberry jam may earn a net return of $\$ 10$ per batch. If the marmalade requires 5 hours of your time, and the jam requires 2 hours of your time, you are earning a higher net return per hour from the strawberry jam ( $\$ 5 /$ hour rather than $\$ 3 /$ hour). Product mix decisions may be interdependent with pricing decisions and complicated by marketing factors, but comparing budgets for different products provides important information for guiding those decisions.

Preparing budgets before investing in a canning enterprise can help you determine whether it will be profitable and whether you can achieve a return that is worth the time spent. In the example budget, you could compare the net return of $\$ 1.85$ per labor hour to the value of alternative uses of your time. Tracking your actual costs and comparing the costs to budget projections can help you refine future budgets and make necessary adjustments to your operation. Preparing separate budgets for each product can provide information for your product mix and pricing decisions. If canning for your own consumption, budgeting allows you to estimate the true cost or savings of the activity. Budgeting is an important practice, whether you are canning for your own household use or as an incomegenerating enterprise.

\section{Tips for Converting Units of}

\section{Measure}

In preparing a budget for home canning, you may need to convert units of measure for ingredients. When the amount of an ingredient you purchase does not match the amount used in a recipe, you will need to convert the cost of the purchase amount to a cost per batch. The budget template does this by dividing the cost of purchase by the number of batches you could make with the amount purchased. Estimating the number of batches you could make with the purchased amount can be complicated when the unit of measure for the purchased quantity does not match the unit of measure for the recipe. The following information is provided to help you estimate the number of recipe batches from the amount purchased.

Ingredient units of measure may be either volume units or weight units. Volume refers to the amount of space an ingredient occupies. Weight refers to the heaviness or mass of an ingredient. For example, cup is a volume measure, but pound is a weight measure. Common volume measures include teaspoon, tablespoon, cup, pint, quart, gallon, and liter. Common weight measures include ounce, pound, and gram. Although ounce is a measure of weight, a fluid ounce is a measure of volume. For example, a US fluid ounce is one-eighth of a cup (Aqua-Calc 2017a).

Converting a volume unit to a different volume unit (or weight unit to weight unit) will always use the same conversion factor, regardless of the ingredient (assuming the ingredient is in the same state). For example, there are always 4 cups in a quart and 16 ounces in a pound. However, the conversion from weight to volume or vice versa depends on the specific ingredient. For example, 16 ounces of honey is 1.34 cups; 16 ounces (weight, not fluid ounces) of vinegar is 1.9 cups; and 16 ounces of whole strawberries is 3.15 cups (Aqua-Calc 2017b).

You can use the Aqua-Calc websites to help you estimate the number of recipe batches from the amount purchased:

- Food Weight to Volume: https://www.aqua-calc.com/ calculate/food-weight-to-volume

- Food Volume to Weight: https://www.aqua-calc.com/ calculate/food-volume-to-weight

For example, if the recipe calls for seven and a half cups of sugar, but you purchased a 10-pound bag of sugar, you need to know how many cups are in the 10-pound bag. On the Food Weight to Volume website, enter 10 pounds for weight; search for "sugar;" and select "sugar, granulated, white." The conversion to cups will be shown as 22.68 cups. If a recipe batch calls for seven and a half cups of sugar, you can divide 22.68 cups (the number of cups you purchased in a 10-pound bag of sugar) by the recipe amount ( 7.5 cups) to obtain the number of batches you can make with the 10 -pound bag of sugar ( 3 batches).

If a recipe calls for ingredients that are chopped, crushed, pitted, or otherwise changed from the state they were purchased, the conversion of units will be further affected. For example, you purchase one quart of fresh whole blackberries, but the recipe calls for cups of crushed blackberries. Ideally, the recipe will give you an estimate of the amount of a fresh product needed to obtain the required amount of an altered product.

Table 3 illustrates some common conversions (Aquacalc 2017a, 2017b; National Center for Home Food Preservation 2017). 


\section{Summary}

The Budget Template for Home Canning is a tool you can use to estimate the cost and potential returns from canning food. Preparing separate budgets for each product can provide information for your product mix and pricing decisions. If canning for your own consumption, budgeting allows you to estimate the true cost or savings of the activity. Budgeting is an important practice, whether you are canning for your own household use or as an incomegenerating enterprise.

\section{References}

Ahn, S., R. Goodrich-Schneider, and A.H. Simonne. 2014a. "How to Start a Food Business: Introduction." FS254. Gainesville, FL: University of Florida Institute of Food and Agricultural Sciences. http://edis.ifas.ufl.edu/fs254.

Ahn, S., L. House, and R. Goodrich-Schneider. 2014b. "How to Start a Food Business: Writing a Business Plan." FS259. Gainesville, FL: University of Florida Institute of Food and Agricultural Sciences. http://edis.ifas.ufl.edu/ fs259.

Aqua-Calc. 2017a. Food Volume to Weight Conversions. http://www.aqua-calc.com/calculate/ food-volume-to-weight.

Aqua-Calc. 2017b. Food Weight to Volume Conversions. http://www.aqua-calc.com/calculate/ food-weight-to-volume.

D’Sa, E.M., E.L. Andress, J.A. Harrison, and M.A. Harrison. 2007. "Survey of Home Canning Practices and Safety Issues in the United States." Institute of Food Technologists Conference, Chicago, IL. http://nchfp.uga.edu/papers/2007/ canning_survey.html.

EnergyUseCalculator.com. 2017. Energy Use Calculator. http://energyusecalculator.com/electricity_stovetop.htm.

Florida Department of Agriculture and Consumer Services (FDACS). 2017. Cottage Food Operations. http://www. freshfromflorida.com/content/download/70108/1634054/ Cottage_Food_Guidance.pdf.

Florida Legislature. 2016. The 2016 Florida Statutes, Title XXXIII, Chapter 500.80. Cottage Food Operations. http://www.leg.state.fl.us/Statutes/ index.cfm?App_mode=Display_Statute\&Search_ String $=\& U R L=0500-0599 / 0500 /$ Sections $/ 0500.80 . h t m l$.
Kendall, P., and L. Payton. 2008. "Cost of Preserving and Storing Food.” Number 8.704, Food and Nutrition Series, Colorado State University Extension, Fort Collins, CO. http://extension. colostate.edu/topic-areas/nutrition-food-safety-health/ cost-of-preserving-and-storing-food-8-704/.

National Center for Home Food Preservation. 2017. http:// nchfp.uga.edu/index.html.

North Central Regional Extension. 2000. "Selling Food Products: A Business from Your Home." Publication No. 259, AGMRC, Iowa State University, Ames, IA. http://www. agmrc.org/media/cms/NCR259_C51C58D92E63F.pdf

Peoples Gas. 2017. Natural Gas Appliance Calculator. http:// www.peoplesgasdelivery.com/home/gas_calculator.aspx.

US Department of Energy. 2017. Estimating Appliance and Home Electronic Energy Use. https://www.energy.gov/energysaver/ estimating-appliance-and-home-electronic-energy-use. 
Table 1. Canning budget template: blank

\begin{tabular}{|l|l|l|l|l|}
\hline \multicolumn{2}{|l|}{ SPECIFICATIONS } & & \\
\hline Product Name: & & Jar Size: \\
\hline Method: & Amt Purchased & Purchase Cost & Nbr Batches \\
\hline INGREDIENT COSTS & & & \\
\hline Ingredient & & & \\
\hline & & & & \\
\hline & & & & \\
\hline & & & & \\
\hline & & & \\
\hline
\end{tabular}

List ingredients, amount purchased, and cost of purchase. Estimate the number of batches you could make from the amount purchased. Divide the cost of purchase by the number of batches to obtain the cost per batch for each ingredient. Sum the cost per batch for each ingredient to obtain the total ingredient costs per batch.

\section{JAR COSTS}

\begin{tabular}{|l|l|l|l|l|l|}
\hline \multicolumn{2}{|l|}{ Item } & Amt Purchased & Purchase Cost & Nbr Batches & \\
\hline & & & & \\
\hline & Total & & & \\
\hline
\end{tabular}

Fill in this table if the jars will be sold and not returned. List jar items (including jar size, lids, bands, and labels) along with the amount purchased and cost of purchase for each. Calculate the number of batches you could make with the amount purchased. Divide the cost of purchase by the number of batches to obtain the cost per batch. Sum the cost per batch for each item to obtain the total jar costs per batch. If you will reuse jars for multiple batches, leave this section blank and enter jar costs in the durable supply section below.

\begin{tabular}{|l|l|l|l|l|}
\hline \multicolumn{2}{|l|}{ DURABLE SUPPLY \& EQUIPMENT OWNERSHIP COSTS } & Original Cost & Nbr Batches & Cost / Batch \\
\hline Item & & & \\
\hline & & & \\
\hline & & & & \\
\hline & & & & \\
\hline & & & & \\
\hline & & & & \\
\hline & & & & \\
\hline & Total & & & \\
\hline
\end{tabular}

Durable supplies and equipment are tools that will be used for multiple batches before being replaced. List durable supply and equipment ownership costs that are incurred for the canning business. Enter the original cost (purchase price) and the number of batches you expect to produce (of all products) with the tool before replacing it. Divide the original cost by the number of batches to get the cost per batch. If you will (re)sell the item after using it, subtract the resale value from the original cost before dividing by the number of batches. If the tool would be owned with or without the canning business, no cost needs to be entered for the item here. Sum the cost per batch for each item to obtain the total supply costs per batch. 


\begin{tabular}{|l|l|l|l|l|l|}
\hline \multicolumn{2}{|l|}{ Item } & Operating Unit & Cost / Unit & Units / Batch & \\
\hline & & & & \\
\hline & Total & & & \\
\hline
\end{tabular}

List the equipment items that have operating (power) costs. Enter the operating unit (the unit on which operating costs are assessed), the cost per operating unit, and the number of operating units used per batch. Multiply the cost per unit by the units per batch to obtain the cost per batch. Sum the cost per batch for each item to obtain the total equipment operating costs per batch.

\section{LABOR HOURS}

Activity

Preparation time

Processing time

Marketing time

Total

Estimate labor hours per batch, broken down by preparation, processing, and marketing time. Sum the hours for each to get the total labor hours. If any labor is paid, list the labor costs and sum to obtain the total labor cost per batch. Otherwise, leave cost column blank.

\section{COST SUMMARY}

Item

Total / Batch

Ingredient costs

Jar costs

Equipment-operating costs

Labor costs

Variable costs

Durable supply \& equipment ownership costs

Total costs

Variable cost per jar:

Total cost per jar (breakeven price)

Enter totals from other sections here. Variable costs per batch are the sum of ingredient costs, jar costs, equipment-operating costs, and labor costs per batch. Total costs per batch are the sum of all five cost types per batch. To calculate the cost per jar (breakeven price), divide the costs per batch by the number of jars per batch.

\section{SALES REVENUE}

\begin{tabular}{|l|l|l|l|}
\hline \multicolumn{2}{|l|}{ Market } & Price / Jar & Nbr Jars Sold \\
\hline \multicolumn{2}{|l|}{\begin{tabular}{l} 
Enter the selling price per jar and jars sold per batch. Multiply the price per jar times the number of jars sold to obtain the revenue per batch. \\
\hline PROFITABILITY ANALYSIS
\end{tabular}} & Per Batch & Per Jar \\
\hline Metric & & \\
\hline & Net return over variable costs & & Per Labor Hour \\
\hline & Net return over total costs & \\
\hline & Minimum number of batches to payoff initial supply and equipment ownership cost: \\
\hline
\end{tabular}

Subtract variable costs per batch from revenue per batch to obtain net return over variable costs per batch. Subtract total costs per batch from revenue per batch to obtain net return over total costs. Divide by the number of jars per batch to obtain net returns per jar. Divide by the total labor hours to obtain net returns per labor hour. To calculate the minimum number of batches to pay off initial supply and equipment ownership costs, divide the total original cost of the durable supplies and equipment by the net return over variable costs per batch. This estimate assumes the useful life of supplies and equipment is at least as long as the minimum number of batches. 
Table 2. Canning budget template: example

\begin{tabular}{|c|c|c|c|c|}
\hline \multicolumn{5}{|l|}{ SPECIFICATIONS } \\
\hline Product Name: & \multicolumn{2}{|l|}{ Strawberry Jam } & Jar Size: & Half-Pint Jars \\
\hline Method: & \multicolumn{2}{|c|}{ Boiling Water Method } & Jars / Batch: & 8 \\
\hline \multicolumn{5}{|l|}{ INGREDIENT COSTS } \\
\hline Ingredient & Amt Purchased & Purchase Cost & Nbr Batches & Cost / Batch \\
\hline Strawberries (2 quarts) & 2 quarts & $\$ 10.00$ & 1 & $\$ 10.00$ \\
\hline Sugar ( 7.5 cups) & 10-pound bag & $\$ 9.00$ & 3 & $\$ 3.00$ \\
\hline Powdered pectin (1 package) & 2-pack box & $\$ 3.00$ & 2 & $\$ 1.50$ \\
\hline Lemon juice (2 fluid ounces) & 16 fl. oz. bottle & $\$ 4.00$ & 8 & $\$ 0.50$ \\
\hline & & & & \\
\hline Total & & & & $\$ 15.00$ \\
\hline
\end{tabular}

List ingredients, amount purchased, and cost of purchase. Estimate the number of batches you could make from the amount purchased. Divide the cost of purchase by the number of batches to obtain the cost per batch for each ingredient. Sum the cost per batch for each ingredient to obtain the total ingredient costs per batch.

\section{JAR COSTS}

\begin{tabular}{|l|l|l|l|l|l|}
\hline \multicolumn{2}{|l|}{ Item } & Amt Purchased & Purchase Cost & Nbr Batches & Cost / Batch \\
\hline & Half-pint jars (with lids \& bands) & 12 -count & $\$ 12.00$ & 1.5 & $\$ 8.00$ \\
\hline Labels & 60 -count & $\$ 6.00$ & 7.5 & $\$ 0.80$ \\
\hline Total & & & $\$ 8.80$ & \\
\hline
\end{tabular}

Fill in this table if the jars will be sold and not returned. List jar items (including jar size, lids, bands, and labels) along with the amount purchased and cost of purchase for each. Calculate the number of batches you could make with the amount purchased. Divide the cost of purchase by the number of batches to obtain the cost per batch. Sum the cost per batch for each item to obtain the total jar costs per batch. If you will reuse jars for multiple batches, leave this section blank and enter jar costs in the durable supply section below.

\begin{tabular}{|c|c|c|c|c|}
\hline \multicolumn{5}{|c|}{ DURABLE SUPPLY \& EQUIPMENT OWNERSHIP COSTS } \\
\hline \multicolumn{2}{|l|}{ Item } & Original Cost & Nbr Batches & Cost / Batch \\
\hline & Canning pot $\&$ rack (or pressure canner) & $\$ 30.00$ & 60 & $\$ 0.50$ \\
\hline & Canning kit, including & $\$ 20.00$ & 20 & $\$ 1.00$ \\
\hline & Canning funnel & & & \\
\hline & Jar lifter/tongs & & & \\
\hline & Jar wrench & & & \\
\hline & Lid wand & & & \\
\hline & Bubble spatula & & & \\
\hline & Pyrex measuring cups & $\$ 10.00$ & 50 & $\$ 0.20$ \\
\hline & Ladle & $\$ 10.00$ & 50 & $\$ 0.20$ \\
\hline & Knife & $\$ 10.00$ & 50 & $\$ 0.20$ \\
\hline & Slotted spoon & $\$ 10.00$ & 50 & $\$ 0.20$ \\
\hline & Stove & $\$ 0.00$ & & $\$ 0.00$ \\
\hline & Total & $\$ 90.00$ & & $\$ 2.30$ \\
\hline
\end{tabular}

Durable supplies and equipment are tools that will be used for multiple batches before being replaced. List durable supply and equipment ownership costs that are incurred for the canning business. Enter the original cost (purchase price) and the number of batches you expect to produce (of all products) with the tool before replacing it. Divide the original cost by the number of batches to obtain the cost per batch. If you will (re)sell the item after using it, subtract the resale value from the original cost before dividing by the number of batches. If the tool would be owned with or without the canning business, no cost needs to be entered for the item here. Sum the cost per batch for each item to obtain the total supply costs per batch. 
EQUIPMENT OPERATING COSTS

\begin{tabular}{|l|l|l|l|l|l|}
\hline \multicolumn{2}{|l|}{ Item } & Operating Unit & Cost / Unit & Units / Batch & Cost / Batch \\
\hline & Stove, electric usage & Kwh & $\$ 0.12$ & 3 & $\$ 0.36$ \\
\hline & Total & & & & $\$ 0.36$ \\
\hline
\end{tabular}

List the equipment items that have operating (power) costs. Enter the operating unit (the unit on which operating costs are assessed), the cost per operating unit, and the number of operating units used per batch. Multiply the cost per unit by the units per batch to obtain the cost per batch. Sum the cost per batch for each item to obtain the total equipment operating costs per batch.

\section{LABOR HOURS}

Activity

\begin{tabular}{|l} 
Preparation time \\
Processing time \\
Marketing time \\
\hline Total
\end{tabular}

\begin{tabular}{|l|l|}
\hline Hours / Batch & Cost / Batch \\
\hline 1 & $\$ 0.00$ \\
\hline 1 & $\$ 0.00$ \\
\hline 1 & $\$ 0.00$ \\
\hline 3 & $\$ 0.00$ \\
\hline
\end{tabular}

Estimate labor hours per batch, broken down by preparation, processing, and marketing time. Sum the hours for each to obtain the total labor hours. If any labor is paid, list the labor costs and sum to obtain the total labor cost per batch. Otherwise, leave cost column blank.

\section{COST SUMMARY}

Item

Ingredient costs

Total / Batch

Jar costs

$\$ 15.00$

Equipment-operating costs

48.80

Labor costs

$\$ 0.36$

Lariable costs

Variable costs

$\$ 0.00$

Durable supply \& equipment ownership costs

Total costs

$\$ 2.30$

Variable cost per jar:

$\$ 26.46$

Total cost per jar (breakeven price)

$\$ 3.02$

$\$ 3.31$

Enter totals from other sections here. Variable costs per batch are the sum of ingredient costs, jar costs, equipment-operating costs, and labor costs per batch. Total costs per batch are the sum of all five cost types per batch. To calculate the cost per jar (breakeven price), divide the costs per batch by the number of jars per batch.

\section{SALES REVENUE}

\begin{tabular}{|l|l|l|l|l|}
\hline Market & Price / Jar & Nbr Jars Sold & Revenue / Batch \\
\hline
\end{tabular}

Enter the selling price per jar and jars sold per batch. Multiply the price per jar times the number of jars sold to obtain the revenue per batch.

\section{PROFITABILITY ANALYSIS}

Metric

Net return over variable costs

Net return over total costs

\begin{tabular}{|l|l|}
\hline Per Batch & Per Ja \\
\hline$\$ 7.84$ & $\$ 0.98$ \\
\hline$\$ 5.54$ & $\$ 0.69$ \\
\hline
\end{tabular}

Per Labor Hour

$\$ 2.61$

Minimum number of batches to payoff initial supply and equipment ownership cost:

Subtract variable costs per batch from revenue per batch to obtain net return over variable costs per batch. Subtract total costs per batch from revenue per batch to obtain net return over total costs. Divide by the number of jars per batch to obtain net returns per jar. Divide by the total labor hours to obtain net returns per labor hour. To calculate the minimum number of batches to pay off initial supply and equipment ownership costs, divide the total original cost of the durable supplies and equipment by the net return over variable costs per batch. This estimate assumes the useful life of supplies and equipment is at least as long as the minimum number of batches. 
Table 3. Tips for measuring conversions

\begin{tabular}{|c|c|c|c|c|}
\hline \multicolumn{5}{|c|}{ Volume-to-Volume Conversions } \\
\hline & Cup & Pint & Quart & Liter \\
\hline 1 cup $=$ & 1.00 & 0.50 & 0.25 & 0.24 \\
\hline 1 pint $=$ & 2.00 & 1.00 & 0.50 & 0.47 \\
\hline 1 quart = & 4.00 & 2.00 & 1.00 & 0.95 \\
\hline 1 liter $=$ & 4.23 & 2.11 & 1.06 & 1.00 \\
\hline \multicolumn{5}{|c|}{ Weight-to-Weight Conversions } \\
\hline & & Pound & Ounce & Gram \\
\hline 1 pound = & & 1.0000 & 16.0000 & 453.5920 \\
\hline 1 ounce $=$ & & 0.0625 & 1.0000 & 28.3495 \\
\hline 1 gram $=$ & & 0.0022 & 0.0353 & 1.0000 \\
\hline \multicolumn{5}{|c|}{ Weight-to-Volume conversions for Sample Ingredients } \\
\hline \multicolumn{2}{|l|}{ Ingredient } & \multicolumn{3}{|l|}{ Conversion } \\
\hline \multicolumn{2}{|l|}{ Sugar, granulated, white } & \multicolumn{3}{|l|}{1 pound $=2.27$ cups } \\
\hline \multicolumn{2}{|l|}{ Strawberries, whole } & \multicolumn{3}{|l|}{1 pound $=0.79$ quarts } \\
\hline \multicolumn{2}{|l|}{ Blueberries, whole } & \multicolumn{3}{|l|}{1 pound $=0.77$ quarts } \\
\hline \multicolumn{5}{|c|}{ Example Estimates of Recipe Units per Package for Sample Ingredients } \\
\hline Ingredient & \multicolumn{2}{|l|}{ Package Size Purchased } & Recipe Unit & Units / Pkg \\
\hline Sugar & \multicolumn{2}{|l|}{10 pounds } & Cup & 22.7 \\
\hline Apple juice & \multicolumn{2}{|l|}{1 gallon (128 fl. oz.) } & Cup & 16 \\
\hline Lemon juice & \multicolumn{2}{|l|}{1 quart (32 fl. oz.) } & Cup & 4 \\
\hline Vinegar & \multicolumn{2}{|l|}{2 quarts (64 fl. oz.) } & Cup & 8 \\
\hline Strawberries & \multicolumn{2}{|l|}{2 pounds } & Quart & 1.58 \\
\hline Blueberries & \multicolumn{2}{|l|}{18 ounces } & Quart & 0.86 \\
\hline Blackberries & \multicolumn{2}{|l|}{1 quart, fresh } & Cup, crushed & 2 \\
\hline
\end{tabular}

